\title{
GPS based TEC measurements for a period August 2008- December 2009 near the northern crest of Indian equatorial ionospheric anomaly region
}

\author{
S P KARIA* and K N PATHAK** \\ SV National Institute of Technology, Ichhanath, Surat, Gujarat 395 00\%, India. \\ *Corresponding author.e-mail: kariasheetal@yahoo.co.in \\ **e-mail: knp@ashd.svnit.ac.in
}

In recent years, measurements of total electron content (TEC) have gained importance with increasing demand for the GPS-based navigation applications in trans-ionospheric communications. To study the variation in ionospheric TEC, we used the data obtained from GPS Ionospheric Scintillation and TEC monitoring (GISTM) system which is in operation at SVNIT, Surat, India $\left(21.16^{\circ} \mathrm{N}, 72.78^{\circ} \mathrm{E}\right)$ located at the northern crest of equatorial anomaly region. The data collected (for the low sunspot activity period from August 2008-December 2009) were used to study the diurnal, monthly, seasonal semi-annual and annual variations of TEC at Surat. It was observed that the diurnal variation at the region reaches its maximum value between 13:00 and 16:00 IST. The monthly average diurnal variations showed that the TEC maximizes during the equinox months followed by the winter months, and are lowest during the summer months. The ionospheric range delay to TEC for the primary GPS signal is $0.162 \mathrm{~m}$ per TECU. The diurnal variation in TEC shows a minimum to maximum variation of about 5 to 50 TECU (in current low sunspot activity periods). These TEC values correspond to range delay variations of about 1 to $9 \mathrm{~m}$ at Surat. These variations in the range delay will certainly increase in high sunspot activity periods. Detected TEC variations are also closely related to space weather characterizing quantities such as solar wind and geomagnetic activity indices.

\section{Introduction}

The GPS has become an efficient tool for studying the ionospheric variability in past few years. The GPS signal propagating through the ionosphere are advanced in phase and delayed in time. This time delay being a function of electron density when measured by using a dual frequency receiver can compute the TEC (the total number of electron encountered along a particular line-of-sight by the propagating wave). From the difference between the two frequency measurements, the TEC along the signal path between GPS and the receiver can be calculated. Unit of TEC is TECU $=10^{16}$ electrons per square meter. The ionospheric delay constitutes the main source of error for singlefrequency GNSS operation. The sensitivity of the ionospheric range delay to TEC for the primary GPS signal is $0.162 \mathrm{~m}$ per TECU. Hence, the range delay for this signal can reach as much as $90 \mathrm{~m}$ for a low-elevation satellite (e.g., Langley 1996).

The ionization in the equatorial and Polar regions is known to be high compared to relatively moderate levels of electron content in the mid-latitude ionospheric regions (Kane 1980). TEC at the mid-latitudes are relatively small compared to the equatorial and low-latitude regions (Davies 1980). The studies on the latitudinal variation of

Keywords. Total electron content; equatorial ionization anomaly (EIA) region; ionosphere; wave propagation; GPS. 
the electron density in the Indian sector have been carried out with the availability of the orbiting satellites, such as BE-B and BE-C, INTASAT and the geostationary satellites, such as ATS-6, ETS-2 and SIRIO; several researchers have made significant contributions by making individual measurements of TEC from various locations in India (Rastogi and Sharma 1971; Dasgupta and Basu 1973; Rastogi et al 1975; Iyer et al 1976; Rama Rao et al 1977; Davies et al 1979) and the broad features in the behaviour of the equatorial ionization anomaly (EIA) are brought out. It is known that the equatorial ionization anomaly is a result of the 'fountain effect', which is the consequence of the effect of the equatorial electrojet interaction with the horizontal (N-S) Earth's magnetic field at the equator which gives rise to a lifting of the equatorial plasma to higher altitudes, during most of the daytime hours. This plasma subsequently diffuses along the geomagnetic field lines to either side of the magnetic equator owing to the effects of ambipolar diffusion, gravity and pressure gradients, giving rise to an accumulation of ionization at the F-region altitudes around $\pm 15^{\circ}$ geomagnetic latitudes, resulting in the formation of crests of ionization.

\section{Data and analysis for TEC measurement using Global Positioning System}

The GSV 4004 Ionospheric Scintillation Monitor receivers (GISM) collect the TEC and scintillation data (Van Dierendonck et al 1996). Each GISM can track up to 11 GPS C/A-code signals at the L1frequency of $1.575 \mathrm{GHz}$. The data is collected at one minute, which do not include the $50-\mathrm{Hz}$ sampled raw data, but the reduced TEC and S4 index and other parameters are included. To extract TEC from the GPS observation file, the pseudorange measurements on L1 $(1.5754 \mathrm{GHz})$ and L2 $(1.2276 \mathrm{GHz})$ frequencies have been considered. The ionospheric delay can be expressed in terms of the signal carrier frequency as follows:

$$
\delta_{\text {ion }}\left(f_{c}\right)=\frac{40.3 \cdot T E C}{f_{c}^{2}}
$$

where $\delta_{\text {ion }}\left(f_{c}\right)$ is the signal propagation delay at a given carrier frequency.

$$
S T E C=\int_{0}^{S} N d r=\left(\frac{f_{2}^{2}}{f_{1}^{2}-f_{2}^{2}}\right) \frac{2 f_{1}^{2}}{K} \Delta P_{1,2}
$$

where $\Delta P_{1,2}=$ difference between time delays measured by the L1 and L2, $K=40.3 \mathrm{~m}^{3} \mathrm{~s}^{-1}, f_{1}=$ frequency of the L1 wave, and $f_{2}=$ second frequency (L2 wave).

In the above equation (2.2), there is a bias error correction which is different for different satellite- receiver pairs. Sardon et al (1994) reported that if accurate estimates of the ionospheric TEC are to be obtained, the differential instrumental biases must be removed. Many scientists have developed technique to derive GPS-TEC (Coco et al 1991; Leick 1995; Liu et al 1996). In the present study, the receiver part of the above bias is corrected by taking the value supplied by the manufacturer by calibrating the receiver against wide area augmentation system (WAAS). As we are mainly concerned with variations of TEC, the above approach is satisfactory. This procedure gives the corrected slant TEC. The slant TEC measurements made are the sum of the real slant TEC, the GPS satellite differential delay $b_{S}$ (satellite bias) and the receiver differential delay, $b_{R}$ (receiver bias). Except when at the zenith, the GPS satellite transmits the signal to the reference station through the ionosphere at some oblique angle. To remove the effect of the increased path length due to obliqueness, the $S T E C$ needs to be multiplied by a slant factor, $S(E)$.

Therefore, the vertical TEC can be expressed as:

$$
\begin{aligned}
V T E C & =\left(\frac{S T E C-[b R+b S]}{S(E)}\right) \\
S(E) & =1 /\left(\cos \chi^{\prime}\right)
\end{aligned}
$$

where

$$
\cos \chi^{\prime}=\sqrt{1-\left(\frac{R_{x} \cos \chi}{R_{x}+h_{m}}\right)^{2}}
$$

$R_{x}=$ mean earth radius, $6371 \mathrm{~km}, h_{m}=$ altitude of the IPP, $\chi=$ elevation angle, and $\chi^{\prime}=\left(90^{\circ}-\chi\right)$ (Mannucci et al 1993; Langley et al 2002).

The ionosphere puncture point (IPP) is where the GPS signals travel through the maximum electron density layer of the ionosphere. The mean ionospheric height of $350 \mathrm{~km}$ is used for the determination of IPP locations, which is found to be valid for elevation $>50^{\circ}$ in a low latitude sector (Rama Rao et al 2006). To obtain a good average diurnal variation plot of TEC, all TEC $>50^{\circ}$ elevation are filtered so as to eliminate the low elevation effects, due to multipath and tropospheric scattering on the measured TEC values. To obtain the vertical TEC at Surat, we are restricted to a longitude grid of $\pm 2^{\circ}$ and latitude grid of $\pm 2^{\circ}$ from the observing station, in addition to the $50^{\circ}$ elevation cut-off.

\section{Results and discussions}

The TEC obtained were examined for local time, monthly and seasonal variations. The results are discussed below. 


\subsection{Diurnal variation of TEC}

To illustrate the feature of diurnal variation, mean TEC on a particular day is shown in figure 1 . It can be seen that the TEC decreases slowly from pre-dawn to sunrise period, reaches its minimum at 05:00 IST (IST $=$ Local Time $=\mathrm{UT}+$ 05:30 hrs) and increases steadily till noon, reaches its peak ( 50 TECU) at 16:00 IST and decreases sharply post-sunset. TEC exhibits the usual diurnal variation of a minimum in the pre-sunrise hours (05:00 IST) and a maximum between 13:00 and 16:00 IST. To illustrate the diurnal variation mass plots of diurnal variations at Surat for different months over a period from August 2008-December 2009 (with an exception of October 2008 and January 2009 when observations were disrupted due to technical problems) is shown in figure 2 .

\subsection{Seasonal variation of TEC}

Figure 3 represents monthly mean TEC from February to December 2009 for the region. The morning rise and afternoon decay in TEC is sharp in the equinoxes (March, April, September, and October) 2009. The forenoon rate of production and afternoon decay of ionization is faster in winter (November, December, January, February) 2009 compared to that in summer (May, June, July, August) 2009. The amplitude of the diurnal maximum is higher ( $\sim 40 \mathrm{TECU})$ in the equinoxes and lower in the winter and summer thus exhibiting the semi-annual variation. In order to clearly analyze the trend of seasonal variations of TEC, the average monthly value of TEC and average peak value of TEC monthly were computed. Figure 4 represents the average of monthly TEC value (upper panel) and average of peak TEC value (middle panel) in light of monthly solar flux $10.7 \mathrm{~cm}$ (bottom panel) for a period February 2009 to December 2009. It is observed that annual variation in solar flux $10.7 \mathrm{~cm}$ ranges from 68 to 76 s.f.u (solar flux units). Semi-annual trend is observed in both the average value in the top and middle panels of figure 4 . To analyze the trend further, similar graphs were plotted by considering average TEC of five internationally disturbed days (D-days) for all the months from February to December 2009 and are presented in figure 5(a) and of five internationally quiet days in figure 5(b). It is observed that for the current low sunspot activity, the D-days and Q-days have followed the trend of seasonal variations.

Further, TEC is higher ( $\sim 30$ TECU) in the winter than in the summer ( $\sim 25$ TECU $)$, i.e., the "winter anomaly' in seasonal variation is also observed. The time of occurrence of the diurnal maximum varies with season. In the equinoxes, the morning rise and afternoon decay of TEC is sharp compared to that in summer and winter. TEC reaches its daytime peak earlier ( 13:00 IST) in equinoxes and later ( 15:00 IST) in summer and winter. In summer, the morning pre-dawn value is high and the peak value is low compared to that in equinoxes. In October, the time of occurrence of maximum TEC is earlier and afternoon decay of TEC is very sharp.

The seasonal variations of the ionosphere have been explained in terms of changes in solar zenith angle and thermospheric composition (Rishbeth and Setty 1961) and from global circulations (Millward et al 1996). According to the generally accepted theory, the ionospheric TEC depends on

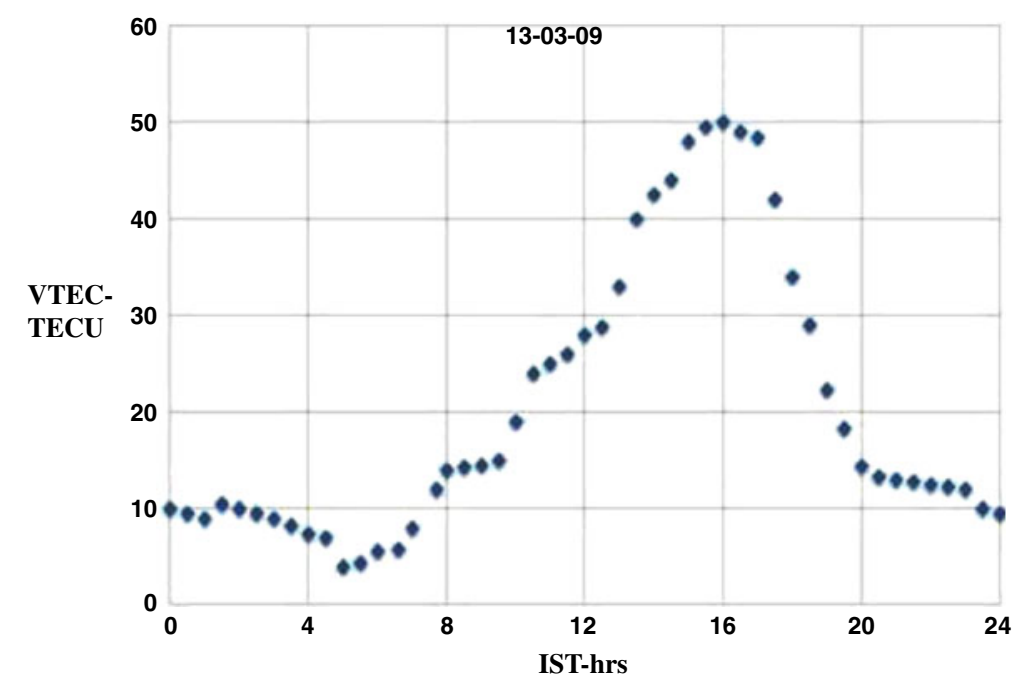

Figure 1. Diurnal variation of vertical TEC with time at Surat for a typical day of 13 March 2009. It can be seen that the TEC decreases slowly from pre-dawn to sunrise period reaches its minimum at 05:00 IST and increases steadily till noon, reaches its peak ( 50 TECU) at16:00 IST and decreases sharply post-sunset. 


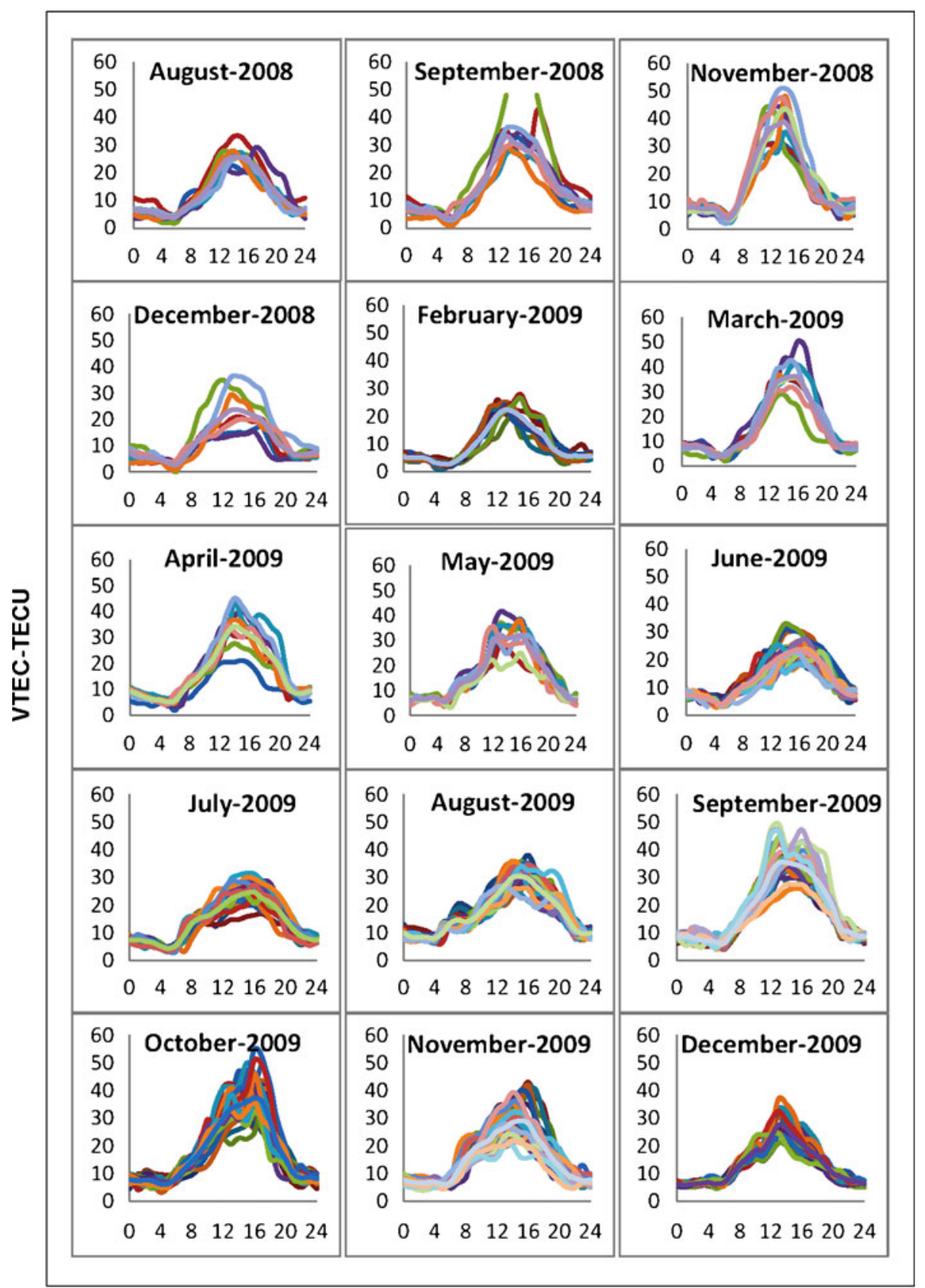

IST-hrs

Figure 2. Mass plots of diurnal variations at Surat for different months over a period from August 2008-December 2009 (with an exception of October 2008 and January 2009 when observations were disrupted due to technical problems).

the atomic/molecular ratio $\left([\mathrm{O}] /\left[\mathrm{N}_{2}\right]\right)$ (Titheridge 1974) as well as the solar zenith angle. Both observations and model simulations illustrate a clear seasonal change in thermospheric composition, specifically with higher $[\mathrm{O}] /[\mathrm{N} 2]$ in winter than in summer. Rishbeth and Setty (1961) suggested that the seasonal anomaly may be associated with atmospheric composition changes. The topside ionosphere is not in photochemical equilibrium and transport becomes one of the principal processes. Thus, besides neutral compositions, neutral winds should play an important role in the seasonal variations of TEC. Thermospheric winds push plasma up and down geomagnetic field lines and transport plasma from one hemisphere to the other by modulating the field-aligned flows, which influences the latitude structure of plasma (Watanabe et al 1995) and the observed hemispheric asymmetries. Neutral winds in the magnetic meridian include contributions from both the geographic zonal and meridional winds, which depend on the magnetic declination angle. Therefore, the fieldaligned flows due to neutral winds may be a primary cause of the latitudinal and longitudinal 


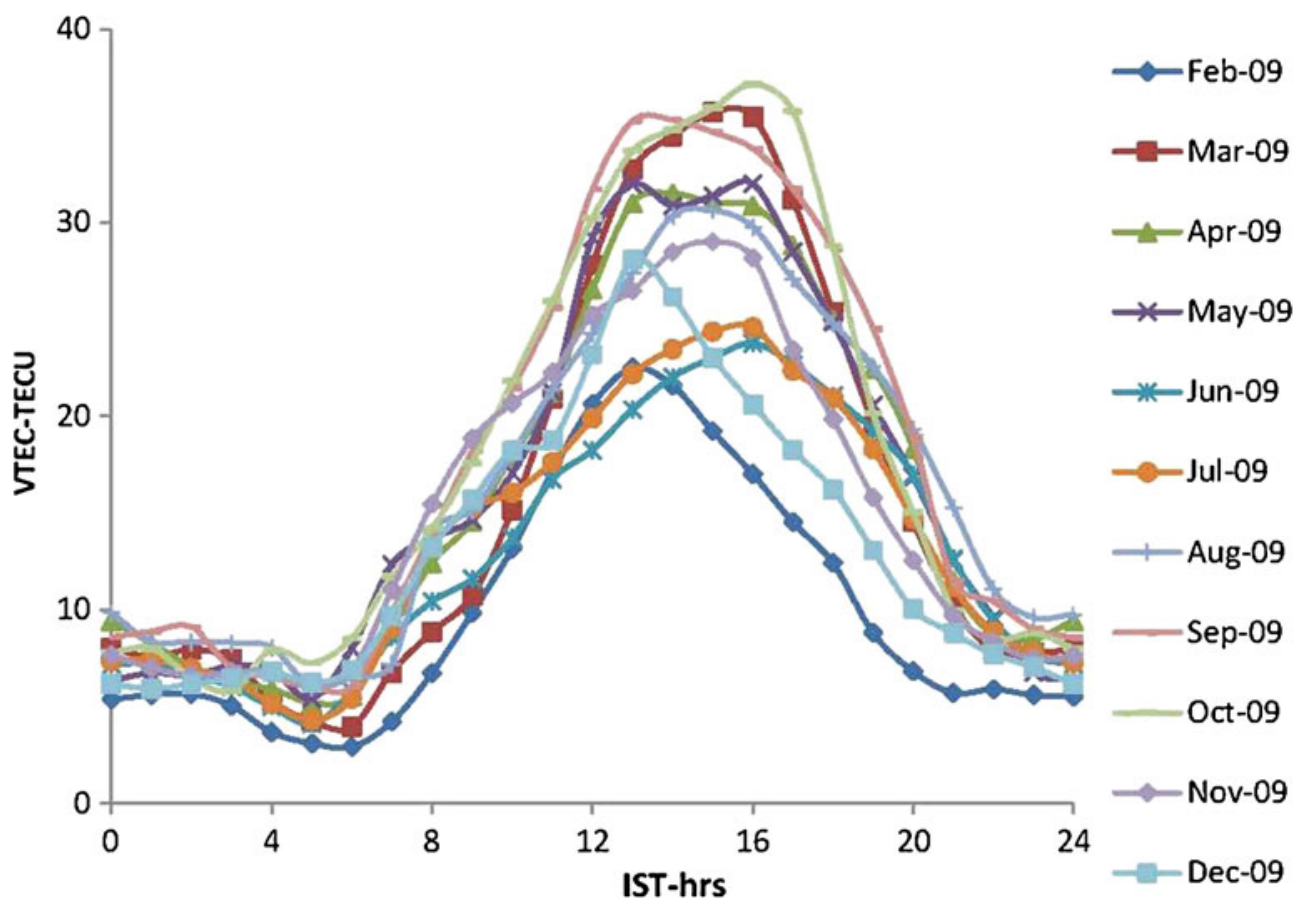

Figure 3. Monthly mean VTEC from February to December 2009.

dependences and the seasonal variations of the topside plasma densities (e.g., Bailey et al 2000; Balan et al 1997, 2000; Su et al 1998). The seasonal variations of meridional winds may contribute to influence the seasonal variations of TEC, especially at which the thermospheric wind effects are particularly strong.

One noticeable important TEC feature is the day-to-day variability, particularly during the midday to pre-dawn hours. The day-to-day variability is of great importance to the development of empirical models. Day-to-day variability of equatorial and low latitude $\mathrm{F}$ region ionosphere in the Indian zone has been studied by Dabas et al (2006). As discussed by Forbes et al (2000) and FullerRowell et al (2000), the day-to-day variability, which is greater in the region of the equatorial ionization anomaly (EIA) area and at high latitudes, is attributed to solar, geomagnetic, and other causes which seem to be originated from lower part of the atmosphere, were termed 'meteorological' by (Rishbeth and Mendillo 2001). The meteorological processes such as planetary waves, gravity waves, and tides can have direct or indirect effects on the ionosphere (Laštovička 2006; Rishbeth 2006).

\subsection{TEC and space weather parameters}

The term 'space weather' refers to the conditions on the Sun and in the solar wind, magnetosphere, ionosphere and thermosphere that affect the performance and the reliability of technological systems on Earth and in space. Space weather processes can include changes in the interplanetary magnetic field, solar flares, coronal mass ejection from the Sun, and disturbances in the Earth's magnetic field. These processes could be studied
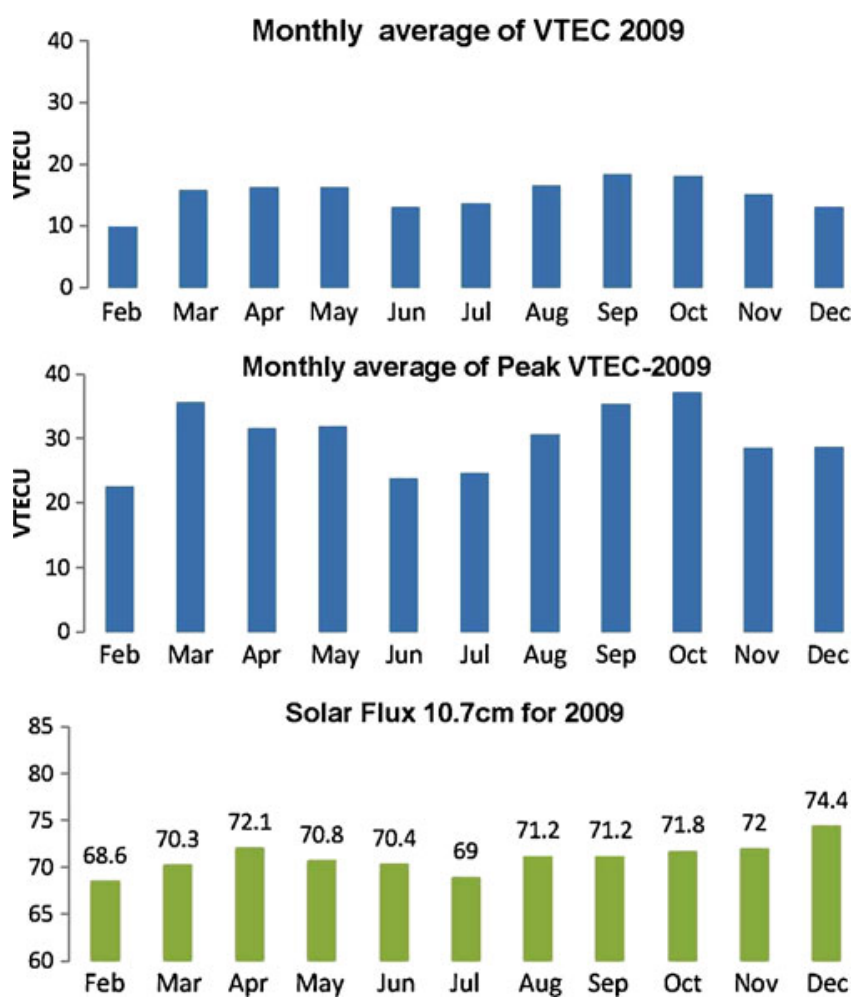

Figure 4. The average of monthly VTEC value (upper panel) and average of peak TEC value (middle panel) in light of monthly solar flux $10.7 \mathrm{~cm}$ (bottom panel) for a period February 2009 to December 2009. 

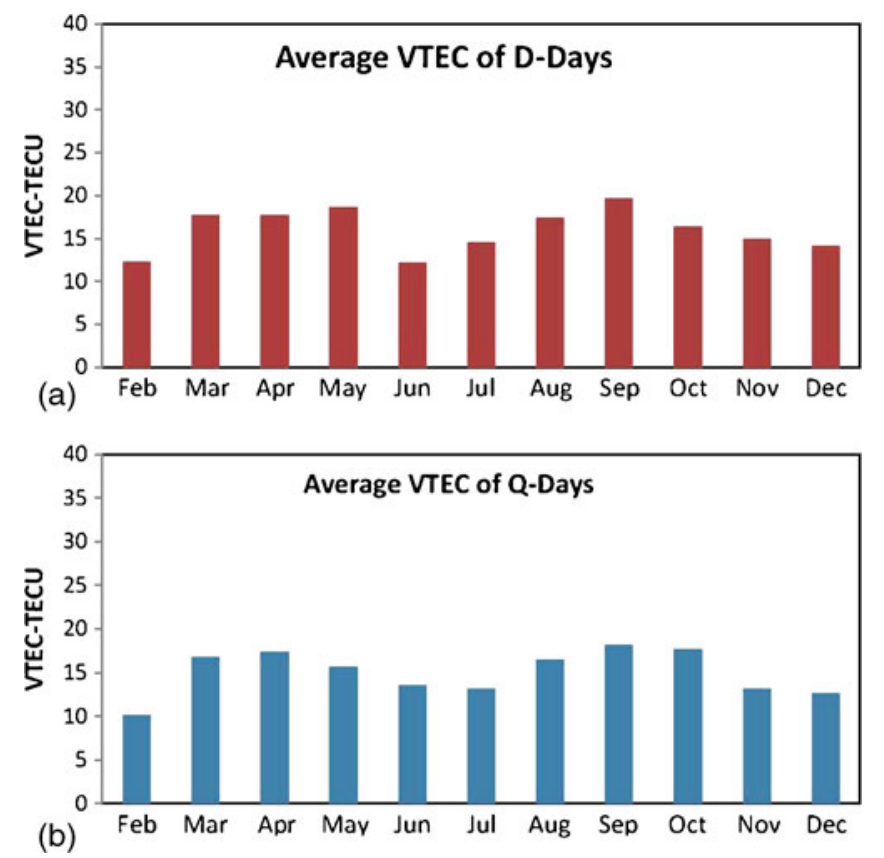

Figure 5. (a) The graph plotted by considering the average VTEC of five internationally disturbed days (D-days) for all the months from February 2009 to December 2009. (b) The graph plotted by considering the average VTEC of five internationally quiet days (Q-days) for all the months from February 2009 to December 2009.

through the solar wind parameters such as proton velocity $(\mathrm{Vp})$, proton density $(\mathrm{Np})$ as well as inter planetary magnetic field component $(\mathrm{Bz})$. Many organizations around the world are now actively engaged in monitoring, modelling and predicting the space weather. Violent eruption in the Sun's outer atmosphere on November 8, 2000, spewed billions of tons of charged particles towards the earth and caused severe turbulence in the space around the Earth (Burch 2001). One of the consequences of severe space weather is often the disruption to satellite communications and even disruption of power grid on the Earth. GPS navigation accuracy is greatly affected by the space weather, as it is particularly sensitive to changes in the electron density in the ionosphere. Ionospheric storm phenomena are shown to be closely related to space weather characterizing quantities such as solar radio emission, solar wind speed and geomagnetic activity indices (Jakowski et al 2001). As the present period is falling under solar minimum conditions, the probability of encountering the disturbed ionosphere is very low (Basu and Basu 1981; Aarons 1982). To see the variation in TEC with respect to the space weather parameters, a geomagnetically disturbed day, 4 September 2009 (Dst = $-50 \mathrm{nT}$ ), has been selected from the period of study. The level of geomagnetic activity during the examined period is indicated by the $\mathrm{Kp}$ index issued by World Data Center for Geomagnetism,
Kyoto. The Kp index describes geomagnetic conditions at mid-latitudes, and the Dst index describes geomagnetic conditions at low latitudes. Solar wind interplanetary magnetic field (IMF) Bz component in the GSM coordinate has been obtained from the ACE satellite. Figure 6 shows the co-relation of TEC with the various parameters like Kp, Dst, interplanetary magnetic field $\mathrm{Bz}$, solar wind parameters proton velocity, $\mathrm{Vp}$ and proton density, $\mathrm{Np}$

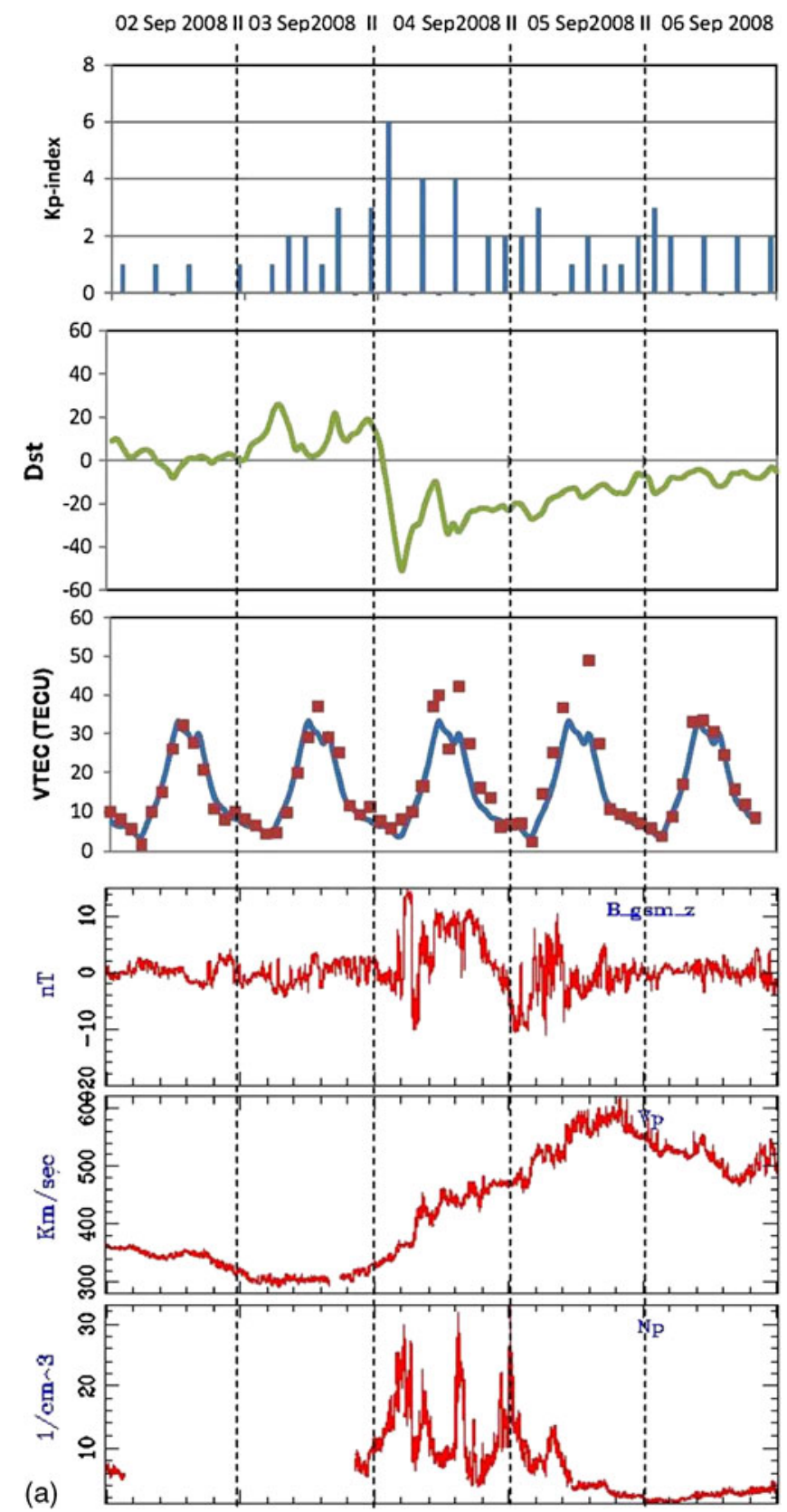

Figure 6. (a) The variations of Dst, Kp (first and second panels from top) and VTEC (red dotted line) during 2-6 September 2008 are shown. The mean VTEC of the month is shown by the solid blue line in the third panel. The variations of interplanetary magnetic field $\mathrm{Bz}$, solar wind velocity $\mathrm{Vp}$, and proton density Np during the period of 2-6 September are shown in the fourth, fifth and sixth panel from top. (b) $\mathrm{O} / \mathrm{N}_{2}$ variation for 3-4 September 2009 . 

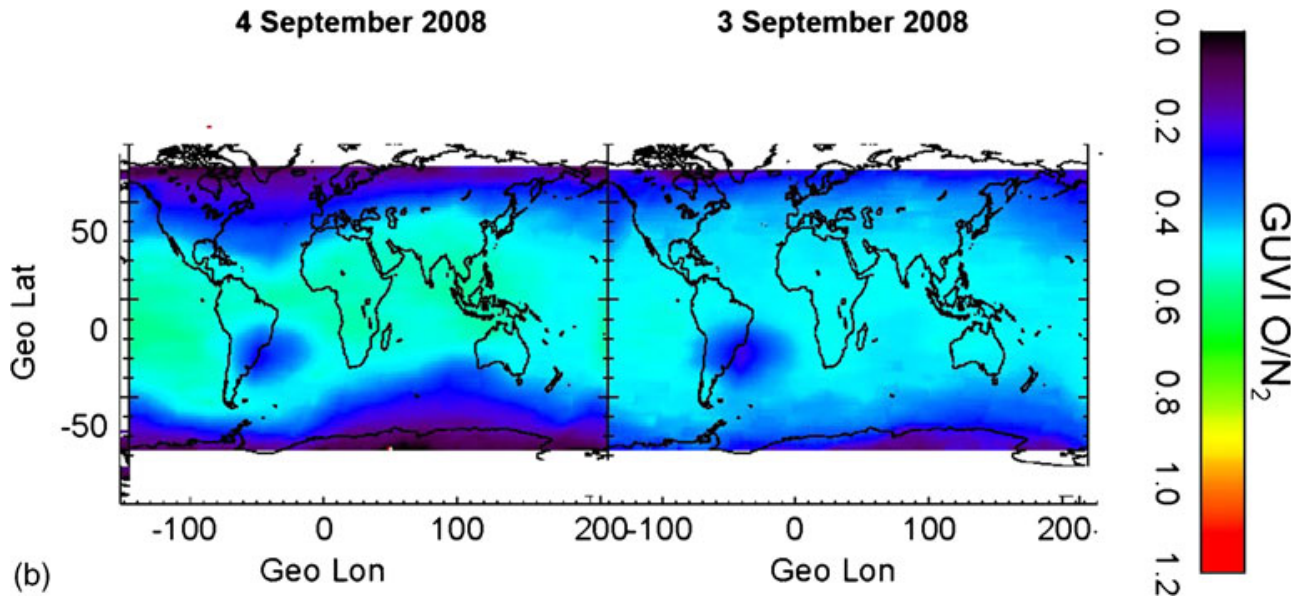

Figure 6. (Continued).

for the period 2-6 September 2008. Figure 6(b) shows TIMED/GUVI image for $\mathrm{O} / \mathrm{N}_{2}$ distribution on 3 September 2008 and 4 September 2008. It can be observed that the $\mathrm{O} / \mathrm{N}_{2}$ decreased at high latitudes and enhanced at lower latitudes on 4 September compared to that on 3 September. Thus, the event from 2-6 September may be considered as a positive storm effect with the enhancement of $\mathrm{O} / \mathrm{N}_{2}$ at low and mid-latitude (Field et al 1998). It has been shown that TEC is a quite useful parameter to design perturbations in the magnetosphere/ionosphere/thermosphere systems. The GPS technique provides a unique opportunity to monitor the perturbations in space weather parameters, continuously on global scale in near real time.

\section{Conclusions}

The diurnal, monthly and seasonal variations of TEC derived from Surat $\left(21.16^{\circ} \mathrm{N}, 72.78^{\circ} \mathrm{E}\right)$ located at the northern crest of equatorial anomaly region are studied for the low sunspot activity period from August 2008 to December 2009. The measured TEC exhibits features like the equatorial ionization anomaly, seasonal, monthly and day-to-day variability. The diurnal variation at the region reaches its maximum value between 13:00 and 16:00 IST. Similarly, the day minimum in TEC occurs between 05:00 and 06:00 IST. The monthly average diurnal variations show that the TEC maximizes during the equinox months followed by the winter months, and are lowest during the summer months. The lower values of TEC during the summer months may be attributed to the low ionization densities, due to the reduced production rates (indicated by $\mathrm{O} / \mathrm{N}_{2}$ ratio). Further, seasonal variations of meridional winds may contribute to influence the seasonal variations of TEC, especially at which the thermospheric wind effects are particularly strong.

The ionospheric range delay to TEC for the primary GPS signal is $0.162 \mathrm{~m}$ per TECU. The diurnal variation in TEC shows a minimum to maximum variation of about 5 to 50 TECU (in current low sunspot activity periods). These TEC values correspond to range delay variations of about 1-9 $\mathrm{m}$ at Surat. These variations in the range delay will certainly increase in high sunspot activity periods. The observed variation in TEC has shown strong relation with the space weather parameters for the selected event (2-6 September 2008).

\section{Acknowledgements}

Our thanks to World Data Centre for Geomagnetism, Kyoto, for providing us the Dst and Kp values. We thank ACE Science Centre for providing us the ACE data. We thank NASA Data Center for providing us TIMED/GUVI images and NOAA Data Centre for providing us Solar F10.7 flux values.

\section{References}

Aarons J 1982 Global morphology of ionospheric scintillations; Proceedings of IEEE $\mathbf{7 0} 360-378$.

Bailey G J, Su Y Z and Oyama K-I 2000 Yearly variations in the low latitude topside ionosphere; Ann. Geophys. 18 789-798.

Balan N, Otsuka Y and Fukao S 1997 New aspects in the annual variation of the ionosphere observed by the MU radar; Geophys. Res. Lett. 24 2287-2290.

Balan N, Otsuka Y, Fukao S, Abdu M A and Bailey G J 2000 Annual variations of the ionosphere: A review based on MU radar observations; Adv. Space Res. 25(1) 153-162.

Basu S and Basu Su 1981 Equatorial scintillations - a review; J. Atmos. Terr. Phys. 43 473-479.

Burch J L 2001 The fury of space; Scientific American, April 2001, pp. 72-80.

Coco D S, Cockers Dahlke S R and Clynch J R 1991 Variability of GPS satellite instrumental group delay 
biases; IEEE Trans. Aerosp. Electron. Syst. 27(6) 931-938.

Dabas R, Sharma N, Pillaia M G K and Gwal A 2006 Dayto-day variability of equatorial and low latitude $\mathrm{F}$ region ionosphere in the Indian zone; J. Atmos. Sol.-Terr. Phys. 68 1269-1277.

Dasgupta A and Basu A 1973 Investigation of ionospheric electron content in the equatorial region as obtained by orbiting beacon satellites; Ann. Geophys. 29 409-419.

Davies K 1980 Recent progress in satellite radio beacon studies with particular emphasis on the ATS-6 Radio beacon experiment; Space Sci. Rev. 25 357-430.

Davies K, Donnelly R F, Grubb R N and Rama Rao P V S 1979 ATS-6 satellite radio beacon measurements at Ootacamund, India; Radio Sci. 14 85-95.

Field P R, Rishbeth H, Moffett R J, Idenden D W, Millward G H and Aylward A D 1998 Modelling composition changes in F-layer storms; J. Atmos. Sol.-Terr. Phys. 60 523-543.

Forbes J M, Palo S E and Zhang X 2000 Variability of the ionosphere; J. Atmos. Sol.-Terr. Phys. 62 685-693.

Fuller-Rowell T J, Codrescu M and Wilkinson P 2000 Quantitative modelling of the ionospheric response to geomagnetic activity; Ann. Geophys. 18 766-781.

Iyer K N, Deshpande M R and Rastogi R G 1976 The equatorial anomaly in ionospheric total electron content and the equatorial electrojet current strength; Proc. Indian Acad. Sci. 84 129-138.

Jakowski N, Heise S and Wehrenpfennig A 2001 TEC monitoring by GPS - A possible contribution to space weather monitoring; Phys. Chern. Earth (C) 26 609-613.

Kane R P 1980 Irregular variations in the global distribution of total electron content; Radio Sci. 15 837-842.

Langley R 1996 Propagation of the GPS signals; In: GPS for geodesy (eds) Kleusberg A and Teunissen P (Berlin Heidelberg New York: Springer), pp. 103-140.

Langley R, Fedrizzi M, Paula E, Santos M and Komjathy A 2002 Mapping the low latitude ionosphere with GPS; GPS World 13(2) 41-46.

Laštovička J 2006 Forcing of the ionosphere by waves from below; J. Atmos. Sol.-Terr. Phys. 68 479-497.

Leick A 1995 GPS Satellite Surveying (New York: John Wiley), 560p.

Liu J Y, Tsa H F and Jung T K 1996 Total electron content obtained by using the global positioning system; Terr. Atmos. Ocean Sci. (China) 7 107-117.
Mannucci A J, Wilson B D and Edwards C D 1993 A new method for monitoring the earth's ionospheric total electron content using the GPS global network; Proc. ION GPS-93, Institule of Navigation, pp. 1323-1332.

Millward G H, Moffett R J, Quegan S and Fuller-Rowell T J 1996 Ionospheric F2 layer seasonal and semiannual variations; J. Geophys. Res. 101 5149-5156.

Rama Rao P V S, Srirama Rao M and Satyam M 1977 Diurnal and seasonal trends in TEC values observed at Waltair; Indian J. Radio 8 Space Physics 6 233-235.

Rama Rao P V S, Gopikrishnan S, Niranjan K, Prasad D S V V D and Uma G 2006 On the validity of the ionospheric pierce point (IPP) altitude of $350 \mathrm{~km}$ in the Indian equatorial and low latitude sector; Ann. Geophys. 24 2159-2168.

Rastogi R G and Sharma R P 1971 Ionospheric electron content at Ahmedabad (near the crest of equatorial anomaly) by using beacon satellite transmissions during half a solar cycle; Planet. Space Sci. 19 1505-1517.

Rastogi R G, Iyer K N and Bhattacharyya J C 1975 Total electron content of the ionosphere over the magnetic equator; Curr. Sci. 44 531-533.

Rishbeth H and Mendillo M 2001 Patterns of F2-layer variability; J. Atmos. Sol.-Terr. Phys. 63 1661-1680.

Rishbeth H and Setty C S G K 1961 The F-layer at sunrise; J. Atmos. Terr. Phys. 21 263-276.

Sardon E, Rius A and Zarraoa N 1994 Estimation of the transmitter and the receiver differential biases and the ionospheric total electron content from Global Positioning System observations; Radio Sci. 29(3) 577-586.

Su Y Z, Bailey G J and Oyama K-I 1998 Annual and seasonal variations in the low-latitude topside ionosphere; Ann. Geophys. 16 974-985.

Titheridge J E 1974 Changes in atmospheric composition inferred from ionospheric production rates; J. Atmos. Terr. Phys. 36 1249-1254.

Van Dierendonck A J, Fenton P and Klobuchar J 1996 Commercial ionospheric scintillation monitoring receiver development and test results; Proc. Institute of Navigation's 52nd Annual Technical Meeting, Cambridge, MA, pp. 573-582.

Watanabe S, Oyama K-I and Abdu M A 1995 Computer simulation of electron and ion densities and temperatures in the equatorial $\mathrm{F}$ region and comparison with Hinotori results; J. Geophys. Res. 100(A8) 14,581-14,590. 